\title{
On Trying to Do Things with Words
}

\author{
Another plan-based approach to speech act interpretation
}

\author{
Michael J. Hußmann \\ Heinz Genzmann ${ }^{1}$ \\ FB Informatik, Universität Hamburg \\ Rothenbaumchaussee 67-69 \\ D-2000 Hamburg 13, West Germany \\ e-mail: hussmann@rz.informatik.uni-hamburg.dbp.de
}

\begin{abstract}
Alvstract
Usual plan-based approaches to speech act interpretation require that performing a speech act implies its success. These approaches are thus useless for describing failing illocutionary or perlocutionary acts. We propose an vilternative plan-based view of speech acts centered around the notion of trying to do -- as opposed to actually doing - an action. This approach is contrasted with that of Perrault which aims to overcome similar problems.
\end{abstract}

\section{Introduction}

The plan-based approach to the analysis of natural language dialogues, inspired by the work of Austin [Austin 62] and Searle [Searle 75] [Searle/Nanderveken 85], has dominated most of the dialogue-oriented NLU research since the late seventies, of. [Allen 79], [Allen 84], [Cohen 78], [Cohen/Perrault 791, [Perrault/Allen 801, [Litman 85], [Pollack 86]. It is characterized by the following assurnptions:

- Utterances are actions planned and executed by the speaker to satisfy some of her goals.

- Speech acts can be represented as operators in planning systems such as STRIPS [Fikes/Nilsson 71] which relate actions to their preconditions and effects.

- The speaker's beliefs and intentions can be inferred by observing her utterances.

Several variants of describing actions in planning systems have been proposed in the literature. We will use the following conventions: an action is defined by a quintuple comprising

- an action description, e.g. (pick-up ?x) in the blocks world domain,

- a set of preconditions, e.g. (on-table ?x),

- the add-list, $a$ set of propositions which become true once the action has been performed, e.g. (holding ?x),

- the deleterlist, a set of propositions which are no longer true after the action has been performed, e.g. (on-table ?x),

- the body, a list of lower-level actions comprising the described action, e.g. the movements of a robot arm in the blocks world domain.
The relationship between these elements is interpreted as conditional generation (following [Goldman 70], [Pollack 86]): the execution of the body actions gener ates the defined action (and thus its effects as described in the add-and delete-list) iff the preconditions hold.

All three acts involved in making an utterance, the lo. cutionary, illocutionary, and perlocutionary acts, may fail: the addressee may not hear the utterance, she may not understand the speaker, or she may not react according to the speaker's intentions.

But when actions are defined in terms of their effects, a failure to achieve the effects implies a corresponding failure to perform the action. When I try to drive a nail into the wall with a hammer, and fail, then I have not driven a nail into the wall. Similarly, when I utter a declarative sentence, and fail to convince the hearer, I have failed to perform the intended perlocutionary act. When the addressee does not understand me, I have not even performed an illocutionary act, and so on. Regardless of the level of description there's always the chance that the action may fail, i.e. that there was no action. Even granted that we could capture practically all of the relevant cases by describing the action on the level of, say, producing sounds, there's no way to relate that level of description to the intentions of the speaker.

This is a rather unfortunate result, as we take the observed action as the starting point for inferring the speakers beliefs and intentions - which may well be the same, regardless of the speech act's success. Clearly, an approach facilitating a uniform treatment of succeeding and failing speech acts would be most welcome.

There are two ways to cope with failing speech acts. The first amounts to weakening the inference from the performance of an action to its effects being achieved, i.e. making it defeasible. The other solution is to describe actions in terms not presupposing their successful execution. The former approach was proposed by Perrault [Perrault 87] and further refined by Appelt and Konolige [Appe]t/Konolige 88], while the latter is the one we use.

\section{Perrault's approach}

Perrault describes the way assertions influence peoples beliefs by distinguishing between axioms describing strong evidence for beliefs, and default rules capturing the effects of (sometimes failing) speech acts. The most important axioms are:

1This paper was written by the first author but describes work joinlly undertaken with the second. 


$$
\begin{aligned}
& \text { Memory: } \quad \vdash \mathrm{B}_{\mathrm{x}, \mathrm{t}} \mathrm{p} \supset \mathrm{B}_{\mathrm{x}, \mathrm{t}+1} \mathrm{~B}_{\mathrm{x}, \mathrm{t}} \mathrm{p} \\
& \text { Persistence: } \quad \vdash \mathrm{B}_{\mathrm{x}, \mathrm{t}+1} \mathrm{~B}_{\mathrm{x}, \mathrm{t}} \mathrm{p} \supset \mathrm{B}_{\mathrm{x}, \mathrm{t}+1} \mathrm{p} \\
& \text { Observability: } \vdash \mathrm{DO}_{\mathrm{x}, \mathrm{t}} \mathrm{a} \& \mathrm{DO}_{\mathrm{y}, \mathrm{t}} \mathrm{Obs}(\mathrm{x}) \supset \\
& \mathrm{B}_{\mathrm{y}, \mathrm{t}+1} \mathrm{DO}_{\mathrm{x}, \mathrm{t}^{\mathrm{a}}}
\end{aligned}
$$

Agents remember their previous beliefs (memory), they stick to what they believe they believed previously (persistence). If an agent observes another agent, she knows of all actions the observed agent performs (observability). Memory and persistence together imply that agents never forget and never change their beliefs. Observing is regarded as the only dependable mode of acquiring new knowledge.

Speech acts are considered to be a weaker kind of evidence, and thus the effect of uttering a declarative sentence is modelled by default rules:

$$
\begin{array}{ll}
\text { Declarative rule: } & \mathrm{DO}_{\mathrm{x}, \mathrm{t}}(\mathrm{p} .) \Rightarrow \mathrm{B}_{\mathrm{x}, \mathrm{t}} \mathrm{p} \\
\text { Belief transfer: } & \mathrm{B}_{\mathrm{x}, \mathrm{t}} \mathrm{B}_{\mathrm{y}, \mathrm{t}} \mathrm{p} \Rightarrow \mathrm{B}_{\mathrm{x}, \mathrm{t}} \mathrm{p}
\end{array}
$$

i.e., an agent believes what she thinks other agents believe, provided this is consistent with her previous beliefs (belief transfer rule). Uttering a declarative sentence implies by default that the speaker believes its propositional content (declarative rule).

For the most part, this theory makes correct predictions. For example:

- The hearer will not be convinced by an assertion if it contradicts one of her previous beliefs.

- A liar will not be convinced by her own lie, but may still believe that she successfully deceived the unsuspecting hearer.

In both of these cases do the axioms (memory and persistence) override the defaults.

However, adopting Perrault's solution has the unfortunate side effect of depriving speech act rules of their definitional import: an action may be executed without its effects being achieved. What are the effects anyway? According to Perrault, uttering a declarative sentence implies (by default) that the speaker believes its propositional content - this can hardly be thought of as an $e f$. fect of the speech act, and it isn't a precondition, either. As neither the effects of an assertion nor its constituting body actions are specified, this leaves assertions as a primitive, undefined notion. But what is a theory of assertions worth if it does not say what an assertion is or what would count as "making an assertion"?

There's also another, more technical problem: when a speaker has no belief whatsoever about $P$, she can convince herself that $P$ is true by simply uttering " $P$.": as it's perfectly consistent for her to believe $P$, both of the declarative rule and the belief transfer rule are applicable and will lead to her believing $P$. Thus, a speaker may convince herself of anything she is incompetent of.

As Appelt and Konolige have shown, this deficiency can be overcome by employing a more sophisticated nonmonotonic theory, cf. [Appelt/Konolige 88]. But is this added complexity really necessary? Even though Appelt and Konolige claim (without proof) that there can be no specification of the effects of an assertion that applies under all possible circumstances, we aim to achieve just that. Instead of assuming that speech acts sometimes fail to achieve their normal effects, we admit that in fact no (successful) speech act was performed in these cases and relate the speakers behaviour to the intended act by some other means, namely by making explicit the notion of "trying".

\section{Trying to do things with words}

The missing link between an agent's intentions and her (sometimes unsuccessful) performance of the intended action is the notion of "trying": when an agent has a pre. sent directed intention to $A$ (cf. [Bratman 87]), she will try to do $A$, and - if the preconditions for doing $A$ are satisfied - she will thereby do A. Fig. 1 illustrates this:

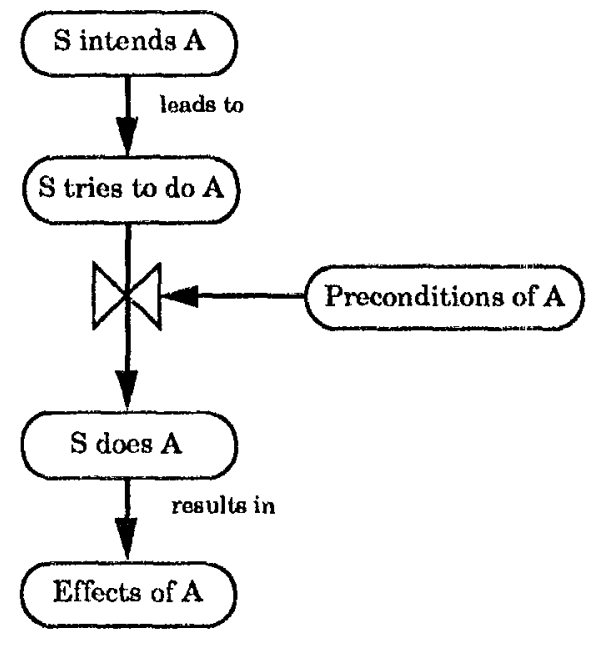

Fig. 2: From intention to action

The try-to-do level of description provides an ideal basis for analyzing the agent's intentions, as such an analysis is independent of the action's success.

The interpretation process uses a default rule to determine whether an action was executed successfully:

From try-to-do to do: If it is known that an agent $S$ tries-to-do $A$ in the situation $S I T_{A}{ }^{2}$, then assume (by default) that $S$ does $A$ in $S I T_{A}$.

The consequence of this conclusion is modelled by another (non default) rule:

From action to effect: If an agent $S$ does $A$ in the situation $S I T_{A}$, then the preconditions of $A$ are satisfied in a situation $S I T_{p}$ temporally including $S I T_{A}$ (because otherwise it would have been impossible to $d o A$ ), and the effects of $A$ are satisfied in a situation $S I T_{E}$ temporally met by $S I T_{A}$.

If this conclusion contradicts a previous belief, the default assumption that $S$ had successfully done $A$ is defeated.

Here lies one of the main differences between Perrault's approach and our's: where he uses defaults for the inference from the performance of an action to its effects, we use defaults for the inference from try-to-do to do. The results are similar, but this move allows us to

\footnotetext{
2Perrault associates beliefs and ather propositional attitudes with time points, whereas we use situations as partial descriptions of the world over a time interval. For the purpose of this paper we deliberatly slur over this distinction as it is unimportant for the is. sue at hand.
} 
use strict definitions of speech acts. For example, the peech act assertion is defined as follows:

Action: Assert $P$ (in $S I T_{U}$ )

Preconditions: The hearer believes that the speaker is sincere and competent in $S I T_{U}$.

Add-list: The hearer believes that the speaker believes $P$.

\section{Body: Utter "p." (in $S I T_{U}$ )}

'The effect (as specified in the add-list) is what we take to We the illocutionary point: to achieve that the hearer believes that the speaker believes the propositional content.

Let us assume the following scenario: a speaker $S$ utvers " $P$." (referring to a situation $S I T_{R}$ ) in the situation $\$ I T_{U}$. Sincerity and competence of the speaker can be judged by an observer $O$ (who may be identical to the speaker) using the following rules:

Insincerity of a speaker in uttering an asser-

tion: If it is known to $O$ that for some situation $S I T_{1}$ temporally included in $S I T_{R}, S$ believes $P$ to be false in $S I T_{1}$, then $O$ knows that $S$ is insincere in $S I T_{U}$.

Incompetence of a speaker in uttering an assertion: If it is known to $O$ that for some situation $S I T_{2}$ temporally including $S I T_{R}, S$ has no be-

lief regarding the truth of $P$ in $S I T_{2}$, then $O$

knows that $S$ is incompetent in $S I T_{U}$

To complete the picture, we use a belief transfer rule quite similar to the one Perrault uses, except that it blocks inferences of the form

$$
B_{x} B_{y} B_{x} p \rightarrow B_{x} B_{x} p \rightarrow B_{x} p
$$

which we think are unreasonable: an agent does not adopt the beliefs she thinks other people have of her at least not automatically. Fig. 2 illustrates the overall structure of the interpretation process, which is the : ame for the speaker, the hearer, or any incidental overhearer:

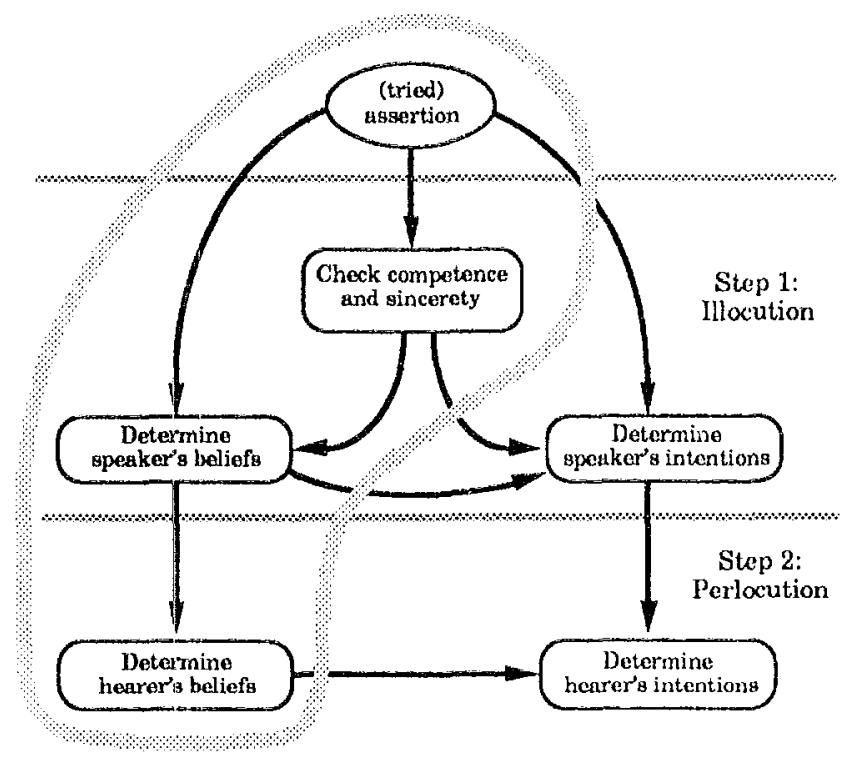

Fig. 2: Interpreting an assertion

The thick gray line encloses the aspects of the interpretation process described in this paper.
An example: the speaker $S$ and the hearer $H$ originally both believe that $-\boldsymbol{P}$. There are no other relevant beliefs. When $S$ utters "P.",

- $S$ recognizes herself to be insincere and thus her assertion - as an utterance to herself - fails. On the other hand, it is consistent for $S$ to believe that $H$ will take her to be competent and sincere by default, and that as an utterance to $H$ the assertion will succeed, i.e. $B_{S} B_{H}{ }^{B} S^{p}$ and thus $B_{S} B_{H} p$.

- $H$ believes $S$ to be competent and sincere by default and therefore the illocutionary act succeeds as an utterance to $H . H$ believes that $S$ believes $P\left(B_{H} B_{S} p\right)$, but sticks to her previous belief that $\neg P$.

As a result, both $S$ and $H$ will continue to believe $\rightarrow P$, but will also (wrongly) attribute to the other a belief that $P$. If instead the speaker had no belief about $P$ initially, she would judge herself incompetent and again would not trust her own words.

Determining the speaker's intentions is considerably more complex, as it requires search in a web of action descriptions linked by (conditionally-) generates and gener. ated-by relations. In general, the observed action $A_{O}$ and the intended action $A_{I}$ are linked by a path

$$
A_{O} \text { generated-by }{ }^{*} \text { generates }{ }^{*} A_{I}
$$

The separation of the analysis of belief and intentions enables a straight-forward interpretation of a speech act's effects while offering a sound basis for the subsequent analysis of the speaker's and hearer's intentions.

\section{Intending to try}

We have described trying-to-do $A$ as an intermediate step between intending to $A$ and doing $A$. An agent may describe her actions as "doing $A$ " or "trying to do $A$ ", and the latter will often just reflect her doubts as to whether she will succeed. Nevertheless, if $A$ is an action, then so is try $A$, and intending to try $A$ is a genuine intention dis tinct from an intention to $A$

In both cases will the intending agent try-to-do $A$, and sometimes do $A$, but even if she fails to do $A$, she cannot fail to try $A$. Trying $A$ will sometimes have the effects of $A$-ing - and, if it does, will have caused these effects but its only necessary result is that $A$ has been tried. Therefore, trying $A$ can be successful where $A$-ing is not. For example, I may intend to try to move a heavy log (cf. [Bratman 87:38f]) while strongly believing I will fail just to demonstrate that I cannot move it. This demon. stration is successful only if I do not succeed in moving the log despite trying real hard to do so.

Bratman (cf. [Bratman 87:111ff]) did not recognize the difference between trying-to-do $A$ as a consequence of intending to $A$ and trying-to-do $A$ as a consequence of intending to try $A$. His term endeavoring (adopted from [Chisholm 76]) encompasses both cases. This missing distinction seems to be responsible for most of the less elegant aspects of Bratman's theory, especially the way he relates acting with an intention to acting intentional$l y$. On the "Simple View", an agents doing $A$ intentionally implies her intention to $A$. Bratman dismisses this Simple View on the grounds that an agent will sometimes act intentionally without (in a strong sense) intending the action. 
Consider the following example taken from [Bratman 87:137]: Bratman very much wants to marry Susan, and he equally much wants to marry Jane. He knows he cannot marry both but is unable to resolve the conflict. Therefore he hopes that Susan and Jane will settle the issue for him: he tries to persuade both women to marry him, expecting that just one of the two will agree. This kind of behaviour seems perfectly rational - though probably immoral - but according to Bratman's strong consistency requirement for intentions he should not intend to persuade Susan and Jane to marry him when he knows he cannot marry both (and thus cannot achieve both perlocutionary acts). Bratman concludes that he intentionally persuades Susan as well as Jane, without endorsing the inconsistent intention to persuade both. Instead he proposes "guiding desires" as a weaker kind of intentions guiding an agents conduct.

We can offer a simpler solution: while sticking to the Simple View, we agree that it is irrational for Bratman to intend to persuade two women to marry him. It is not (necessarily) irrational, however, to intend to try to persuade both women, believing that at most one of the two will agree, and such an intention will lead to the same behaviour towards Susan and Jane as an intention to persuade them simpliciter would. The distinction between stronger and weaker kinds of intentions is therefore unnecessary.

Returning to the issue of speech act interpretation, consider the following case: Mary is tried for a crime she did not commit. She has all the evidence against her, though, and thus she is convinced no one will believe her if she pleads "Not guilty", or even trust her she believes it herself. Unfortunately, Mary cannot rationally intend to assert she is innocent when she is certain of her failure, so what could she do? Again, the intention to try comes to the rescue: poor Mary may rationally intend to try to assert she is innocent (as she has every reason to do so), and this intention will lead to her uttering "Not guilty".

\section{What has been achieved?}

We have developed a descriptive framework to provide a uniform account of successful as well as unsuccessful speech acts. The notion of trying-to-do an action is applicable in both cases and can serve as the basis for analyzing the speaker's intentions. Our theory makes all the correct predictions that Perrault's theory makes, but it does additionally handle the cases which are problematic for Perrault's account.

MEDIAS, a module for speech act interpretation along the lines of the approach presented here has been implemented using the expert system shell HARES as a rapid prototyping tool [Genzmann 89]. MEDIAS handles assertions as well as yes/no questions, distinguishing in. formation-seeking from information-probing questions.

We are currently investigating the role of natural lan. guage utterances in initiating, planning, and coordinating cooperative behaviour (cf. [Werner 89]). This research will build upon and extend the first prototype of the MEDIAS system.

\section{References}

[Allen 79] James F. Allen: A Plan Based Approach to Speech Act Recognition. Technical Report TR 121/79, University of 'Toronto, 1979.

[Allen 84] James F. Allen: Recognizing intentions from natural language utterances. In: Michael Brady, Robert C. Berwick (eds.): Computational models of discourse. Cambridge, Massachusetts: The MIT Press 1984. 107-166.

[Appelt/Konolige 88] Douglas Appelt, Kurt Konolige: A Practical Nonmonotonic Theory for Reasoning about Speech Acts. In: Proc. of the 26th Annual Meeting of the ACL, State University of New York at Buffalo, June 1988. 170-178.

[Austin 62] J. A. Austin: How to Do Things with Words. London: Oxford University Press 1962.

[Bratman 87] Michael E. Bratman: Intention, Plans, and Practical Reason. Cambridge, Massachusetts: Harvard University Press 1987.

[Chisholm 76] Roderick Chisholm: Person and Object. LaSalle, Ill.: Open Court 1976.

[Cohen 78] Philip R. Cohen: On Knowing What to Say: Planning Speech Acts. PhD thesis, University of Toronto, 1978.

[Cohen/Perrault 79] Philip R. Cohen, C. Raymond Perrault: Elements of a Plan-based Theory of Speech Acts. In: Cognitive Science, Vol. 3, 1979. $117-212$.

[Fikes/Nilsson 71] Richard E. Fikes, Nils d. Nilsson: STRIPS: A New Approach to the Application of Theorem Proving to Problem Solving. In: Artificial Intelligence, Vol. 2, 1971. 189-208.

[Genzmann 89] Heinz Genzmann: Eine Untersuchung zur automatischen Modellierung natürlichsprachlicher Dialogstrukturen in der Mensch-MaschineKommunikation. Diploma thesis at the Computer Science Department of the University of Hamburg, August 1989.

[Goldman 70] Alvin I. Goldman: A Theory of Human Action. Englewood Cliffs, N.J.: Prentice-Hall 1970.

[Litman 85] Diane Judith Litman: Plan Recognition and Discourse Analysis: An integrated Approach for Understanding Dialogues. Technical Report 170, Dept. of Computer Science, University of Rochester 1985.

[Perrault/Allen 80] C. Raymond Perrault, James F. Allen: A plan-based analysis of indirect speech acts. In: American Journal of Computational Jinguistics, No. 6, Vol. 3, 1980. 167-182.

[Perrault 87] C. Raymond Perrault: An Application of Default Logic to Speech Act Theory. Report CSLI87-90. CSLI, Stanford, California, March 1987.

[Pollack 86] Martha Elizabeth Pollack: Inferring Domain Plans in Question-Answering. Technical Note 403. AI Center, Computer and Information Sciences Division, SRI International, December 1, 1986.

[Searle 75] John R. Searle: A Taxonomy of Illocutionary Acts. In: K. Gunderson (ed.): Language, Mind, and Knowledge. Minneapolis: University of Minnesota Press 1975.

[Searle/Vanderveken 85] John R. Searle, Daniel Vanderveken: Foundations of Illocutionary Logic. Cambridge: Cambridge University Press 1985.

[Werner 89] Eric Werner: Cooperating Agents: A Unified Theory of Communication and Social Structure. In: M. Huhns, L. Gasser (eds.): Distributed Artificial Intelligence, Vol. 2. Morgan Kaufman and Pitman Publishers, 1989 